\title{
APAKAH MODEL DELONE DAN MCLEAN MAMPU MENJELASKAN KEBERHASILAN SISTEM INFORMASI JKN MOBILE?
}

\author{
Desiana E.Sugesti, Ulfah Hidayati, Sugiarti \\ Jurusan Akuntansi, Politeknik Negeri Semarang Jalan Prof. Soedarto, S. H. \\ Tembalang Semarang \\ ulfah2112@gmail.com;Sugiarti.polines@gmail.com; sugiarti.polines@gmail.com
}

\begin{abstract}
We investigate the Delone \& Mclean success system model on JKN-Mobile in the Indonesian Social Security Provider for Health - BPJS. The research was conducted through a direct survey of users of the JKN mobile system to the Health Social Security Administrators at the Semarang City Office. The data is processed using Structural Equation Modeling, namely the SmartPLS application. The results showed that the quality of JKN Mobile services affected the system to use. User satisfaction is determined by the quality of information, system quality, and service quality of the JKN Mobile system, which affects the benefits of the JKN Mobile system. This study has contributed to the success of the system at the success model JKN mobile applications used extensively and intensively.
\end{abstract}

\section{Keyword: System Succesfulness Delone\& Macleon Success System Model, JKN Mobile, Partial Least Squares, System Succesfulness}

\begin{abstract}
Abstrak:Kami mengkaji model keberhasilan sistem Delone \& Mclean pada JKNMobile di Penyelenggara Jaminan Sosial Indonesia Kesehatan - BPJS. Penelitian dilakukan melalui survei langsung terhadap pengguna sistem mobile JKN pada Penyelenggara Jaminan Sosial Kesehatan di Kantor Kota Semarang, yang diolah dengan menggunakan Structural Equation Modeling yaitu aplikasi SmartPLS. Hasil penelitian menunjukkan bahwa kualitas layanan JKN Mobile mempengaruhi sistem yang digunakan. Kepuasan pengguna ditentukan oleh kualitas informasi, kualitas sistem, dan kualitas layanan sistem JKN Mobile yang mempengaruhi manfaat sistem JKN Mobile. Penelitian ini memberikan kontribusi terhadap keberhasilan sistem pada model keberhasilan aplikasi mobile JKN yang digunakan secara ekstensif dan intensif.
\end{abstract}

Kata Kunci : Model Kesuksesan Sistem Delone \& Macleon, JKN Mobile, Partial Least Square, Keberhasilan Sistem 


\section{PENDAHULUAN}

Perkembangan teknologi informasi (TI) terkini, secara nyata telah memberikan dampak signifikan pada pola operasi entitas bisnis (Elliott, 1992). Berbagai entitas juga telah menjadikan perkembangan TI menjadi sumber daya dan keunggulan kompetitif bisnis (Porter \& Millar, 1985)Sumber daya TI memberikan dampak peningkatan produktivitas, kualitas produk, kepuasan layanan dan memberikan keyakinan layanan kepada konsumen serta menjadi perangkat pendukung keputusan bisnis yang relevan (Ardiansah, Chariri, \& Januarti, 2019).

Sumber daya TI memberikan dampak terhadap bisnis melalui perubahan sistem informasi bisnis, yang mampu menghasilkan informasi yang reliabel, akurat, dan relevan untuk pengambilan keputusan bisnis (Ismail, Abdullah, \& Tayib, 2003). Berbagai penelitian terkait dampak TI terhadap sistem informasi bisnis lebih diarahkan terfokus pada aspek perilaku daripada aspek teknis secara mendalam (Ardiansah, Chariri, Rahardja, \& Udin, 2020; Gordon \& Miller, 1976; Hopwood, 1987). Berbagai kajian terkait isukeperilakuan yang berkembang luas tersebut antara lain membahasisu keberhasilan sistem selain adopsi sistem, keinginan menggunakan, kenyamanan dan kepuasan konsumen (Nadler, Chen, \& Lin, 2019). Riset tentang aspek keperilakuan pengguna sistem informasi di Indonesia telah banyak dilakukan, baik di sektor privat (Koo, Wati, \& Chung, 2013; Rahmi \& Puttri, 2018), maupun sektor public (Yuliana, 2016; Apridiyanti, Suharman, \& Adrianto, 2020). Penelitian ini secara eksploratif akan menguji isu tersebut di sector publik karena secara kontekstual, layanan public di negara berkembang sepertiIndonesia mulai menggunakan sistem informasi sebagai dasar bisnis layanan sehingga aspek keperilakuan pengguna sistem informasi perlu diperhatikan (Heeks,
2002; Molla \& Heeks, 2007;Tan \& Suyatno; 2015).

Sejalan dengan peningkatan layanan, maka Badan Penjaminan Jaminan Sosial (BPJS) mengembangkan sistem informasi berupa Jaminan Kesehatan Nasional yang berbasis mobile application (JKN mobile). Layanan ini diharapkan akan mempermudah dan mempercepat layanan kesehatan kepada pengguna BPJS (Septiyani dan Idris, 2019). Aplikasi ini tidak bersifat wajib bagi pengguna BPJS, namun lebih karena kebutuhan pemantauan dan percepatan layanan kepada peserta. Penggunaan yang bersifat suka rela mengakibatkan aspek kesuksesan sistem menjadi indicator utama dari kinerja layanan BPJS (Handayani, Meigasari, Pinem, Hidayanto \& Ayuningtyas, 2018).

Hal ini mengakibatkan kajian kesuksesan sistem informasi JKN mobile penting dilakukan, karena terbatasnya riset yang secara khusus untuk hal itu. Riset sebelumnya oleh Septiyani dan Idris (2019) tidak secara spesifik menguji keberhasilan sistem JKN mobile, terutama mengeksplorasi determinan kesuksesan sistem menurut Delone and McLean (1992; 2002). Analisis dari Ojo, (2017) dan Tona, Carlsson, \& Eom (2012) mengarahkan perlunya menguji kesuksesan sistem dengan model Delone and McLean secara intensif untuk konteks layanan public tertentu. Mengacu pada uraian di atas maka kajian apakah Model Delone dan Mclean mampu menjelaskan keberhasilan sistem informasi JKNMobile, menarik dilakukan.

Model kesuksesan sistem informasi DeLone dan McLean (1992) telah banyak diadopsi oleh para peneliti untuk mengevaluasi pengembangan sistem informasi. Penerapan sistem informasi sebagai backbone proses bisnis yang sukses akan membawa keunggulan bagi organisasi (Mawarni, 2015; Yuliana, 2016). Kesuksesan sistem tersebuttercermin dalam berbagai fungsi utama bisnis seperti akuntansi, 
manajemen operasi, pengelolaan keuangan dan manajemen sumber daya manusia. Keberhasilan dalam penerapan sistem informasi akan mampu menjadi kontributor utama dalam mendukung efisiensi kegiatan operasional, produktivitas, SDM, pemberian layanan dan kepuasan kepada masyarakat(Saputro, Budiyanto, \& Santoso, 2016)). Keberhasilan penerapan sistem informasi sangat tergantung pada kesesuaian harapan antara pengguna dengan kemampuan sistem yang diharapkan pengguna sistem. Pengembangan sistem informasi memerlukan suatu perencanaan dan implementasi yang hati-hati, untuk menghindari penolakan terhadap sistem yang dikembangkan maka diperlukan partisipasi dari pemakai. Partisipasi pemakai pada tiap tahap pengembangan sistem informasi tentunya akan berpengaruh pada tingkat kepuasan pemakai atas sistem yang dikembangkan(DeLone \& McLean, 1992).

Salah satu model pengukuran kesuksesan sistem informasi yang sering digunakan adalah information system success measurement yang dikembangkan oleh DeLone \& McLean (1992) dan terus dimodifikasi dengan model terakhir tahun 2016 (Ojo, 2017). Model awal menggunakan enam variabel yaitu kualitas sistem (system quality), kualitas informasi (information quality), kualitas layanan (service quality), penggunaan (use), kepuasan pengguna (user satisfaction) dan manfaat bersih (net benefit)sesuai untuk sistem informasi yang masih awal digunakan, belummemperhatikan outcome dan impact secara terpisah(Balaban, $\mathrm{Mu}$, \& Divjak, 2013).Pengujian kesuksesan sistem dengan Model Delone dan Mclean (1992) seperti terlihat pada gambar 1 dapat diproposisikan sebagai berikut:

H1 : Kualitas informasi memiliki pengaruh terhadap penggunaan aplikasi JKN Mobile

H2 : Kualitas informasi memiliki pengaruh terhadap kepuasan pengguna JKN Mobile

H3 : Kualitas sistem memiliki pengaruh terhadap penggunaan JKN Mobile

H4 : Kualitas sistem memiliki pengaruh terhadap kepuasan penggunaan JKN Mobile

H5 : Kualitas layanan memiliki pengaruh terhadap pengguna JKN Mobile

H6 : Kualitas layanan memiliki pengaruh terhadap kepuasan pengguna JKN Mobile

H7 : Penggunaan memiliki pengaruh terhadap kepuasan pengguna JKN Mobile

H8 : Penggunaan memiliki pengaruh terhadap manfaat bersih JKN Mobile

H9 : Kepuasan pengguna memiliki pengaruh terhadap manfaat bersih JKN Mobile

Hubungan antar variabel tersebut dapat digambarkan dalam kerangka teoritis pada gambar 1 sebagai berikut

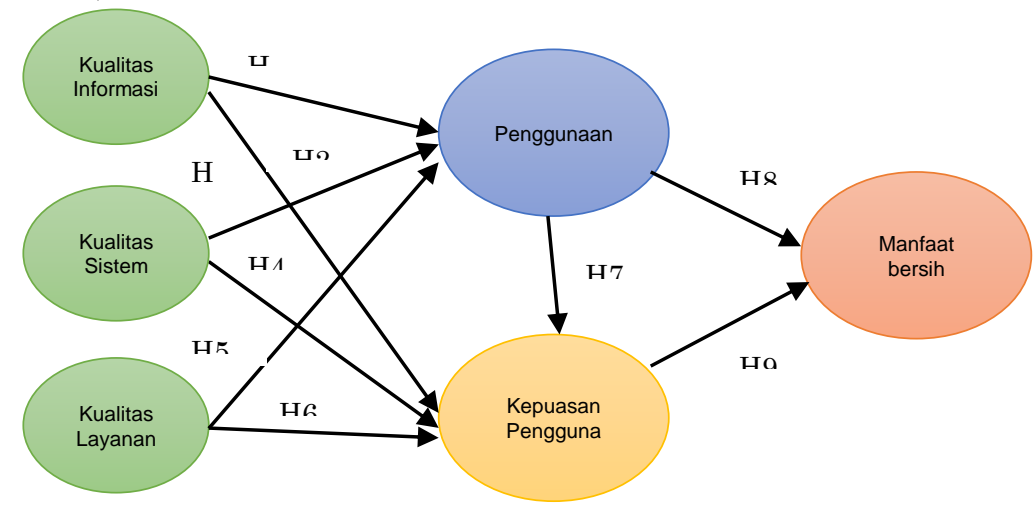

Gambar 1 Kerangka Teoritis 


\section{METODE}

Populasi penelitian ini adalah pengguna JKN mobile dalam wilayah kerja BPJS Kesehatan,Kantor Cabang Utama(KCU) Semarang. Sampel diambil secara judgement samplingyang memiliki karateristik terdaftar sebagai peserta BPJS Kesehatan dan telah menggunakan aplikasi JKN mobile. Kerangka sample diambil dari data kepesertaan dari BPJS KCU Semarang yang secara snowballing dipilih berdasarkan kelompok asal tempat kerja dari sampel tersebut. Data yang diperlukan minimal 100 data untuk dapat dianalisis dengan model persamaan struktural.

Model Delone dan Mclean (1992) mengungkapkan enam variabel, yaitu kualitas informasi kualitas sistem, kualitas layanan, penggunaan, kepuasan pengguna dan manfaat bersih. Setiap variabel diukur dengan indikator pertanyaan yang diukur dengan skala likert.

Analisis model persamaan struktural (structural equational modeD) dengan aplikasi SmartPLS digunakan untuk menguji hubungan antar variabel dalam model Delone dan Mclean. Analisis terbagi menjadi tiga tahapan (Ghozali \& Latan, 2017), pertama pengujian outter measurement model, dengan menentukan terpenuhinya validitas dan reliabilitas variabel endogen dan eksogen, kemudian kedua, pengujian inner - structural model, dengan menentukan terpenuhinya terpenuhinya validitas loading factor dari struktur hubungan antara variabel eksogen dan endogen. Tahap ketiga adalah pengujian goodness of fit model, dengan menentukan terpenuhinya tingkatkesesuain model dalam menjelaskan persaman sesuai konsep Delone dan Mclean (1992). Ghozali (2015) juga menjelaskan bahwa metode analisis yang bersifat soft modelingdengan asumsi partial least square lebih tepat digunakan untuk mengantisipasi asumsidata yang kurang dari 100 dan penilaian persamaan awal, sehingga digunakan dalam analisis penelitian ini.

\section{HASIL DAN PEMBAHASAN}

Pengujian outter modeldilakukan dengan memperhatikan nilai outter loading untuk penilaian convergent validity, nilai cross loading untuk penilaian discriminant validity dan nilai cronbach alpha untuk penilaian composite reliability.

Uji convergent validitydengan menentukan nilai outter loading factordan nilai average variance extracted ( $A V E$ ) untuk tiap indikator dalam satu variabel atau konstruk. Nilai loading factor harus lebih dari 0,7 dan nilai AVE lebih dari 0,5 untuk tiap indikator agar sebuah konstruk dinyatakan valid. Uji Reliabilitas kosntruk dilakukan dengan memperhatikan nilai Cronbach apha dan nilai Composite reliability apakah lebih dari 0,7 untuk dapat diklasifikasikan reliabel. Hasil pengujian outter-measurement model dapat disajikan pada Tabel 1 dibawah ini.

Tabel 1 Uji Validitas, Reliabilitas dan Determinasi Konstruk

\begin{tabular}{|c|c|c|c|c|c|c|}
\hline Indikator & $\begin{array}{c}\text { Kualitas } \\
\text { Informasi }\end{array}$ & $\begin{array}{c}\text { Kualitas } \\
\text { Sistem }\end{array}$ & $\begin{array}{l}\text { Kualitas } \\
\text { Layanan }\end{array}$ & Penggunaan & $\begin{array}{c}\text { Kepuasaan } \\
\text { Pengguna }\end{array}$ & $\begin{array}{c}\text { Manfaat } \\
\text { Bersih }\end{array}$ \\
\hline \multicolumn{7}{|c|}{ Uji Convergent Validity - loading factor } \\
\hline $\mathrm{x} 1$ & 0,676 & 0,672 & 0,788 & 0,905 & 0,874 & 0,762 \\
\hline $\mathrm{x} 2$ & 0,728 & 0,623 & 0,817 & 0,943 & 0,890 & 0,823 \\
\hline x3 & 0,814 & 0,715 & 0,800 & - & - & 0,784 \\
\hline $\mathrm{x} 4$ & 0,674 & 0,797 & - & - & - & 0,809 \\
\hline $\mathrm{x} 5$ & - & 0,739 & - & - & - & - \\
\hline \multicolumn{7}{|c|}{ Uji Convergent Validity - AVE } \\
\hline AVE & 0,673 & 0,689 & 0,711 & 0,789 & 0,725 & 0,703 \\
\hline
\end{tabular}




\begin{tabular}{|c|c|c|c|c|c|c|}
\hline \multicolumn{7}{|l|}{ Uji Reliability } \\
\hline \multirow{2}{*}{$\begin{array}{l}\text { Cronbach apha } \\
\text { Composite } \\
\text { reliability }\end{array}$} & 0,708 & 0,765 & 0,722 & 0,831 & 0,715 & 0,805 \\
\hline & 0,815 & 0,836 & 0,844 & 0,921 & 0,875 & 0,873 \\
\hline \multicolumn{7}{|c|}{ Uji Goodness of Fit Model } \\
\hline $\mathrm{R}^{2}$ & & & & 0,129 & 0,395 & 0,574 \\
\hline Adjusted $\mathrm{R}^{2}$ & & & & 0,101 & 0,370 & 0,565 \\
\hline GoF & & & & & & $49,01 \%$ \\
\hline
\end{tabular}

Sumber: data primer yang diolah, 2020

Tabel 1 menunjukkan bahwa untuk tiap konstruk, sebagian besar memiliki nilai loading factorlebih dari 0,7 ; kecuali untuk indikator $\mathrm{x} 1$ dan $\mathrm{x} 4$ untuk Kualitas informasi, $\mathrm{x} 1$ danx2untuk Kualitas sistem. Meskipun nilai loading factor kurang dari 0,7 namun nilai AVE tidak ada nilai yang kurang dari 0,5 sehingga tiap konstruk pada model Delone dan Mclean ini valid untuk digunakan. Tabel yang sama juga menunjukkan nilai Cronbach alpha dan Composite reliability lebih dari 0,7 sehingga dapat disimpulkan bahwa tiap konstruk diklasifikasikanreliabel untuk digunakan dalam analisis selanjutnya.

Pengujian inner - structural model dilakukan dengan memperhatikan nilai loading dari variabel eksogen ke variabel endogen sebagaimana diilustrasikan pada Tabel 2. Pengujian model ini tidak dapat terpisahkan dengan penilaian kelayakan model (goodness of fit moded), antara lain memperhatikan nilai GoF dan $\mathrm{R}^{2}$. Temuan dari Tabel 1 menunjukkan nilai GoF sebesar $49,01 \%$ yang dapat disimpulkan bahwa model layak dengan kuat karena lebih $40 \%$. Hal tersebut juga didukung oleh nilai $\mathrm{R}^{2}$ dari variabel Manfaat bersih sebesar 57,4 yang menunjukkan bahwa konstruk eksogen sebagai variabel independen menentukan variasi $57,4 \%$ sedang $42,6 \%$ ditentukan oleh variabel lain. Penjelasan sebelumnya disimpulkan bahwa secara struktural dan kelayakan model dapat diterima sehinggapengujian hipotesis dapat dilakukan.

Tabel 2 Tabel Pengujian Hipotesis

\begin{tabular}{lcccc}
\hline & Nilai Loading & Nilai t statistik & Nilai probabilitas & Keputusan \\
\hline $\mathrm{X} 1 \rightarrow \mathrm{Y} 1$ & 0,022 & $\mathbf{0 , 2 0 7}$ & 0,836 & Ditolak \\
$\mathrm{X} 1 \rightarrow \mathrm{Y} 2$ & 0,348 & 3,356 & 0,001 & Diterima \\
$\mathrm{X} 2 \rightarrow \mathrm{Y} 1$ & 0,134 & 1,396 & 0,163 & Ditolak \\
$\mathrm{X} 2 \rightarrow \mathrm{Y} 2$ & 0,199 & 2,157 & 0,031 & Diterima \\
$\mathrm{X} 3 \rightarrow \mathrm{Y} 1$ & 0,282 & 2,591 & 0,010 & Diterima \\
$\mathrm{X} 3 \rightarrow \mathrm{Y} 2$ & 0,316 & 2,904 & 0,004 & Diterima \\
$\mathrm{Y} 1 \rightarrow \mathrm{Y} 2$ & 0,119 & $\mathbf{1 , 2 6 3}$ & 0,207 & Ditolak \\
$\mathrm{Y} 1 \rightarrow \mathrm{Y} 3$ & 0,177 & 2,036 & 0,042 & Diterima \\
$\mathrm{Y} 2 \rightarrow \mathrm{Y} 3$ & 0,686 & 8,508 & 0,000 & Diterima
\end{tabular}

Sumber: data primer yang diolah, 2020 
Tabel 2 diatas menjelaskan bahwa dari sembilan hipotesis, terdapat enam hipotesis ( $\mathrm{H} 2, \mathrm{H} 4, \mathrm{H} 5, \mathrm{H} 6, \mathrm{H} 8$, H9) yang tidak dapat ditolak dan tiga hipotesis (H1, H3, H7) yang ditolak. Pengujian hipotesis tersebut memberikan uraian bahwa Manfaat bersih sistem dipengaruhi secara signifikan oleh Kepuasan pengguna, sedangkan variabel Penggunaan tidak berpengaruh. Variabel Kepuasan pengguna dipengaruhi secara signifikan oleh variabel: Penggunaan, Kualitas informasi dan Kualitas sistem dan Kualitas layanan. Sedangkan variabel Penggunaan dipengaruhi secara signifikan oleh Kualitas layanan, sedang Kualitas informasi dan Kualitas sistem tidak mempengaruhi. Persamaan struktural hubungan antar variabel serta signifikasi hasil pengujian hipotesis dapat diilustrasikan pada gambar berikut:

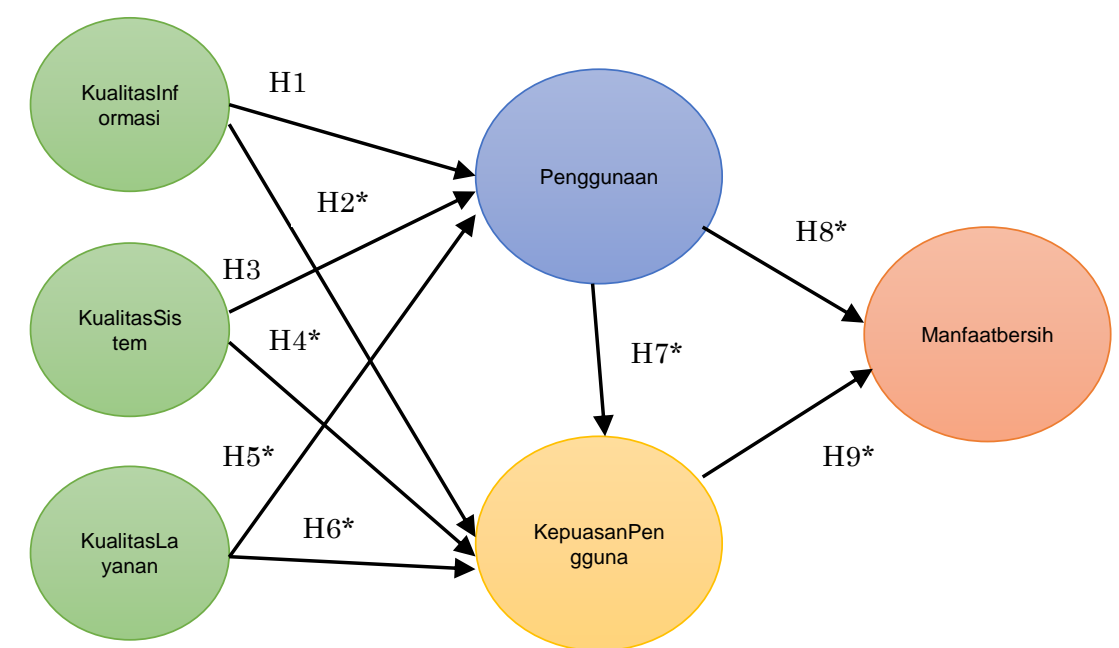

Gambar 2 Hasil Pengujian Hipotesis

Ilustrasi gambar diatas memberikan simpulan bahwa variabel Penggunaan hanya dipengaruhi secara signifikan oleh Kualitas layanan. Hal ini menjelaskan bahwa aspek teknis penggunaan JKN mobile lebih dipersepsikan oleh kualitas layanan sedangkan aspek kualitas informasi dan sistem tidak menjadi perhatian oleh pengguna. Temuan yang menarik bahwa Kepuasan pengguna ternyata ditentukan oleh variabel lain, baik Kualitas informasi, Kualitas sistem dan Kualitas layanan. Hasil ini mendukung temuan dari Seddon \& Kiew (2004); Petter, Delone \& Mclean (2008) dan Mawarni (2015)

Hal ini menunjukkan bahwa kesuksesan sistem JKN mobile sebagai aplikasi yang relatif baru, lebih direflesksikan oleh aspek kepuasan pengguna daripada aspek teknis penggunaan sistem. Manfaat bersih sistem JKN mobile ditentukan secara signifkan oleh Kepuasan pengguna dan Penggunaan, yang ini menggambarkan manfaat bersih kesuksesan sistem dalam model Delone dan Mclean. Manfaat bersih kesuksesan sistem ini yang menjadi acuan model sehingga $\mathrm{R}^{2}$ sebesar $57,4 \%$ dan GoF sebesar 49,01\% menguatkan bahwa model ini mampu menjelaskan kesuksesan sistem JKN mobile.

\section{SIMPULAN}

Hasil penelitian menyimpulkan bahwa model Delone dan Mclean (1992) mempu menjelaskan keberhasilan sistem JKN mobile secara kuat. Kesuksesan sistem lebih ditentukan oleh kepuasan pengguna daripada teknis penggunaan. 
Kualitas sistem, kualitas layanan dan kualitas informasi secara signifikan menentukan Kualitas penggunaan. Penelitian ini diharapkan dapat menjadi tambahan literatur terutama kajian aplikasi sektor publik. Penelitian mendatang dapat secara ekstensif dilakukan baik dengan konteks yang berbeda, baik wilayah demografis maupun jenis aplikasi yang digunakan.

\section{DAFTAR PUSTAKA}

Apridiyanti, A., Suharman, H., \& Adrianto, Z. (2020). Successful Implementation of Information Systems in Public Sector Organizations. Journal of Accounting Auditing and Business, 3(1), 40-51.

Ardiansah, M. N., Chariri, A., \& Januarti, I. (2019). Empirical Study on Customer Perception of E-Commerce: Mediating Effect of Electronic Payment Security. JDA Jurnal Dinamika Akuntansi, 11(2), 122-131. https://doi.org/10.15294/jda.v11i 2.20147 .

Ardiansah, M. N., Chariri, A., Rahardja, S., \& Udin, U. (2020). The effect of electronic payments security on e-commerce consumer perception: An extended model of technology acceptance. Mangement Science Letter, 10(7), 1473-1480. https://doi.org/10.5267/j.msl.201 9.12.020.

Balaban, I., Mu, E., \& Divjak, B. (2013). Development of an electronic Portfolio system success model: An information systems approach. Computers and Education, 60(1), 396-411. https://doi.org/10.1016/j.comped u.2012.06.013.

DeLone, W. H., \& McLean, E. R. (1992). Information systems success: The quest for the dependent variable. Information
Systems Research, 3(1), 60-95. https://doi.org/10.5267/j.uscm.20 14.12.002.

Elliott, R. K. (1992). The Third Wave Breaks on The Shores of Accounting. Accounting Horizons, 6(2), 61-73.

Ghozali, I., \& Latan, H. (2017). Partial Least Squares: Konsep, Teknik dan Aplikasi Menggunakan Program SmartPLS 3.0 untuk Penelitian Empiris (Ed. 2). Semarang: Badan Penerbit Undip.

Gordon, L. A., \& Miller, D. (1976). A contingency framework for the design of accounting information systems. Accounting, Organizations and Society, 1(1), 59-69.

https://doi.org/10.1016/03613682(76)90007-6

Handayani, P. W., Meigasari, D. A., Pinem, A. A., Hidayanto, A. N., \& Ayuningtyas, D. (2018). Criticalsuccessfactorsformobileh ealthimplementation in Indonesia. Heliyon, 4(11), e00981.

Heeks, R. (2002). Information systems and developing countries: failure, success, and local improvisations. Information Society, 18(2), 101-112. https://doi.org/10.1080/01972240 290075039.

Hopwood, A. G. (1987). THE ARCHAEOLOGY OF ACCOUNTING SYSTEMS*. Accounting Organizations and Society (Vol. 12).

Ismail, N. A., Abdullah, S. N., \& Tayib, M. (2003). ComputerBased Accounting Systems: The Case of Manufacturing-Based Small and Medium Enterprises in the Northern Region of Peninsular Malaysia. Jurnal 
Teknologi, $\quad 39(1), \quad 19-36$. https://doi.org/10.11113/jt.v39.47 3

Koo, C., Wati, Y., \& Chung, N. (2013). A study of mobile and internet banking service: applying for IS success model. Asia Pacific Journal of Information Systems, $23(1), 65-86$.

Mawarni, H.A. 2015. Analisis FaktorFaktor yang Mempengaruhi Tingkat Keberhasilan Sistem Aplikasi Lelang Email (ALE) (Studi Kasus pada Kantor Pelayanan Kekayaan Negara dan Lelang (KPKNL) Semarang). Prosding Sentrinov, 001.

Molla, A., \& Heeks, R. (2007). Exploring e-commerce benefits for businesses in a developing country. Information Society, 23(2), 95-108. https://doi.org/10.1080/01972240 701224028

Nadler, S., Chen, A. N., \& Lin, S. (2019). E-payment Usage among Young Urban Chinese. Journal of Business Diversity Vol., 19(3), 75-88.

Ojo, A. I. (2017). Validation of the delone and mclean information systems success model. Healthcare Informatics Research, 23(1), 60-66. https://doi.org/10.4258/hir.2017. 23.1 .60

Porter, M. E. ., \& Millar, V. E. (1985). How information gives you competitive advantage. Harvard Business Review, 64(3), 149160.

Petter, S., DeLone, W. and McLean, E. 2008. Measuring information systems success: models, dimensions, measures, and interrelationships. European
Journal of Information Systems. Vol. 17, pp. 236-263.

Pujo Hari Saputro, A. Djoko Budiyanto, Alb. Joko Santoso. 2015. Model Delone and Mclean untuk Mengukur Kesuksesan Egovernment Kota Pekalongan. Scientific Journal of Informatics. Vol 2.

Rahmi, S., \& Puttri, D. (2018). Testing of ERP (Enterprise Resource Planning) Implementation Success Using Delone and Mclean Model in The Banking Company in West Sumatera. Asia Proceedings of Social Sciences, 2(1), 81-85.

Saputro, P. H., Budiyanto, D., \& Santoso, J. (2016). Model Delone and Mclean Untuk Mengukur Kesuksesan E-Government Kota Pekalongan. Scientific Journal of Informatics, 2(1), 1-8. https://doi.org/10.15294/sji.v2i1. 4523

Seddon P.B. and Kiew, M.Y. 2004. A Partial Test and Development of The DeLone and McLean Model of IS Success. Austrian Journal of Information System, 4(1): 90109.

Septiyani, K. P., \& Idris, H. (2019). Gambaran Kualitas Aplikasi Mobile JKN pada Kalangan Mahasiswa Peserta Jaminan Kesehatan Nasional Di Sumatera Selatan (DoctoralDissertation, Sriwijaya University)

Tan, D., Suyatno, S., \& Aliyah, S. (2015). Pengujian Kesuksesan Sistem Informasi Model Delone \& Mclean Pada Sektor Publik.

Tona, O., Carlsson, S. A., \& Eom, S. B. (2012). An empirical test of Delone and McLean's information system success model in a public organization. 18th Americas Conference on 
JURNAL AKTUAL AKUNTANSI KEUANGAN BISNIS TERAPAN/VOL. 3, NO 1, MEI 2020

ISSN: 2622-6529

e ISSN: 2655-1306

Information Systems 2012, AMCIS 2012, 2, 1374-1382.

Yuliana, K. (2016). Model Kesuksesan Sistem Informasi Delone dan
Mclean Untuk Evaluasi Sistem

Informasi Pos pda PT. Pos

Indonesia (Persero) Divisi Regional VI Semarang. Infokom, No. II Th.(II), 13-23. 